\title{
Recognition of facial expression of the emotions and their relation to attachment styles and psychiatric symptoms. Preliminary study on Psychiatric Residents
}

\author{
Iván Arango de Montis, ${ }^{1}$ Martin Brüne, ${ }^{2}$ Ana Fresán, ${ }^{3}$ Vida Ortega Font, ${ }^{4}$ Javier Villanueva, ${ }^{4}$ \\ Ricardo Saracco,' Jairo Muñoz-Delgado ${ }^{4,5}$
}

Artículo original

\section{SUMMARY}

Facial expressions of emotion reveal complex mental states that have physiological correlates and signal internal states such as distress to others and are thus crucial in social interaction. In this preliminary study, we therefore sought to examine the link between current psychiatric symptoms and attachment styles in psychiatry residents and their ability to correctly identify facial expressions of emotions. Specifically, we hypothesized that greater current psychiatric symptoms and insecure attachment would be related to difficulties in deciphering facial expressions of negative emotions. A total of 56 psychiatry residents were included in the study, together with 50 university students pursuing careers unrelated to mental health. In order to evaluate the subjects' psychiatric symptoms, the Checklist (SCL-90) and Attachment Styles Questionnaire (ASQ) were used and in order to examine the ability to recognize facial expressions of emotion, we chose the Pictures of Facial Affect (POFA). All the respondents gave their informed consent in writing. The control group recognized fear significantly less as compared to psychiatry residents. Among psychiatry residents, there was a significantly positive correlation between hostility and fear recognition and anxiety and fear recognition. The same was observed between obsessive-compulsive symptoms and disgust recognition. In the control group, there was a significantly negative correlation between paranoid ideation and phobic anxiety with sadness recognition. In resident psychiatry, happiness recognition was positively related to an attachment-style based on confidence, while sadness recognition and surprise recognition correlated negatively with an attachment style based on considering relationships as being of secondary importance. This is one of the first studies to examine emotion recognition skills in medical professionals, and the association of this ability with psychiatric symptoms and attachment styles. We think it is important to observe longitudinally what the possible relevance of these findings might be for both diagnostic accuracy and therapeutic relationships.

Key words: Emotion recognition, nonverbal behavior, psychiatric training, medical education.

\section{RESUMEN}

La expresión facial de las emociones revela estados mentales complejos que tienen correlatos fisiológicos y señales de estados internos, como la angustia, y que son esenciales en la interacción social. En el presente estudio preliminar examinamos la asociación entre los síntomas psiquiátricos, los estilos de apego y la habilidad para reconocer correctamente la expresión facial de las emociones básicas, en residentes de psiquiatría de una institución de salud mental de México. La hipótesis es que los síntomas psiquiátricos y el estilo de apego inseguro pueden estar relacionados con una dificultad para descifrar la expresión facial de emociones negativas. Un total de 56 residentes de psiquiatría fueron incluidos en el estudio junto con 50 estudiantes universitarios de la Universidad $\mathrm{Na}$ cional Autónoma de México, UNAM, de carreras diferentes a las relacionadas con la salud mental. Se utilizaron los siguientes instrumentos: Los síntomas psiquiátricos se evaluaron con el SCL-90, traducido y validado al español, el Cuestionario de Estilos de Apego (ASQ) traducido y validado al español, y para el reconocimiento de la expresión facial de las emociones se usó el Instrumento de Ekman, denominado Pictures of Facial Affect (POFA). Previamente, todos los participantes dieron su consentimiento informado con la firma de aceptación para participar en el estudio. Los estudiantes del grupo control reconocieron menos el miedo que los residentes de psiquiatría. En los residentes hubo una correlación positiva entre la hostilidad y el reconocimiento del miedo y entre la ansiedad y el reconocimiento del miedo. Lo mismo se observó entre los síntomas obsesivos-compulsivos y el reconocimiento del disgusto. En el grupo control se encontró una correlación negativa entre la ideación paranoide y la ansiedad fóbica con el reconocimiento de la tristeza. En los residentes el reconocimiento de la felicidad se relacionó positivamente con el estilo de apego basado en la confianza, mientras que el reconocimiento del miedo y la sorpresa fueron negativamente relacionados con el estilo de apego basado en considerar las relaciones como secundarias. Este es un primer estudio que examina la habilidad de reconocer las emociones básicas en profesionales de la medicina que están siendo entrenados en la especialidad de psiquiatría, y la relación con síntomas psiquiátricos y estilos de apego. Consideramos importante el estudio de estos factores a lo largo de la formación, por la posible relevancia que estos hallazgos puedan tener para el adecuado diagnóstico y la relación terapéutica.

Palabras clave: Reconocimiento de la emoción, conducta no verbal, formación en psiquiatría, educación médica.

Servicios Clínicos, Instituto Nacional de Psiquiatría Ramón de la Fuente Muñiz (INPRF).

University Hospital, Ruhr-University Bochum, Germany.

Subdirección de Investigaciones Clínicas, INPRF.

Laboratorio de Cronoecología y Etología Humana. Dirección de Neurociencias, INPRF.

Facultad de Psicología, UNAM

Corresponding: Jairo Muñoz-Delgado. Laboratorio de Cronoecología y Etología Humana. Dirección de Neurociencias. Instituto Nacional de Psiquiatría Ramón de la Fuente Muñiz. Calz. México-Xochimilco 101. San Lorenzo-Huipulco, Tlalpan, 14370, México, DF. Tel: (52-55) 4160 - 5068. E-mail: munozd@imp.edu.mx

Recibido primera versión: 20 de marzo de 2012. Segunda versión: 28 de agosto de 2012. Aceptado: 27 de septiembre de 2012. 


\section{INTRODUCTION}

Facial expressions of emotion reveal complex mental states that have physiological correlates and indicate internal states such as distress to others and are thus crucial in social interaction. ${ }^{1}$ Conversely, imprecision or failure to correctly interpret emotional information as revealed in facial expressions may be a cause for interpersonal and social conflict. ${ }^{2}$ For instance, the smile is the behavioral phenotype conveying a positive internal state such as happiness., Perhaps, unsurprisingly from an evolutionary perspective, the nonverbal communication of negative internal states is associated with a broader range of emotional expressions, which includes fear, anger, disgust and contempt, as well as more complex emotions such as jealousy, envy or excitement.

In addition to the evolutionary relevance of signaling experienced adversity to con-specifics, primate research has shown that conditioning early in life has a major impact on the situational context in which fear is expressed. ${ }^{5}$ Consistent with primate research, humans with high levels of social anxiety tend to misinterpret social cues, ${ }^{6}$ suggesting that the subjective evaluation of other's emotional state is influenced by one's own state of mind. This proneness to misinterpreting information from facial expressions in individuals with high levels of trait anxiety may be linked to insecure attachment. Consistent with this assumption, Guterman ${ }^{7}$ reported difficulties in accurately decoding facial expressions of emotion in people with insecure attachment (both anxious and avoidant). The concept of attachment styles refers to the patterns of expectations, needs, emotions and social behaviors resulting from a particular history of experiences that usually begin in early infancy in the relationship with the parents. A person's attachment style (the patterns of the infant's response to the separation from and reuniting with the primary caretaker) is associated with "internal work models". These mental structures shape a simulated reproduction of previous interactions with attachment figures and primary caretakers, with which, through a person's development, he forms an idea of himself and others and a structure or cognitive script through which he processes social information. ${ }^{8}$

Attachment styles have been divided into four categories: secure, insecure-avoidant, insecure-anxious and disorganized-disoriented. A secure attachment style in infancy is associated with greater cognitive flexibility. The insecure-avoidant attachment style is associated with the deactivation of the attachment system and cognitive suppression strategies. The insecure-anxious attachment style is associated with the hyperactivation of the attachment style and cognitive redirection, while the disorganized, disoriented attachment style is associated with dissociative phenomena. ${ }^{9}$ A neglected aspect of mental health care is the fact that recognition and interpretation of emotional signals can not only be altered in patients with mental illness, but can also vary in mental health professionals, depending on their psychological state of mind. ${ }^{10,11}$

Research using ethological methodology has revealed, however, that the correct identification of patients' facial expressions of emotions and other nonverbal signals is essential, because nonverbal behavior is much less under conscious control than verbal report and therefore yields important information about a patient's "real emotional state", including motivation ambivalence in suicidal patients. ${ }^{12-15}$ Unfortunate$1 y$, these aspects are under-represented in clinical education and have led to greater reliance on subjective patient reports and rating scales. Individual differences in attachment styles in mental health professionals have been taken even less into account in regard to emotion recognition abilities.

In a pioneering study, Csukly et al. ${ }^{16}$ applied the Virtual Human Interface, an instrument comprising the seven basic emotions (happiness, surprise, anger, disgust, fear, sadness, and neutral). In this study, two sets of seven photographs were given to each person. This instrument was used to examine the ability of psychology and medicine students to correctly recognize facial expressions of emotion. In addition, subjective well-being was examined using the Symptom Checklist (SCL-90). As expected, recognition of facial expression of emotions was inversely correlated with symptom severity. Specifically, students with higher scores on the SCL-90 had greater difficulty in recognizing anger and neutral facial expressions. However, the study did not report on whether or not early attachment experience had an influence on students' ability to recognize facial emotions. However, the authors conclude that the difficulty of processing the recognition of the facial expression of emotion is linked to anguish and the severity of psychiatric symptoms.

In this study, we therefore sought to examine the association of current psychiatric symptoms and attachment style in psychiatry residents with their ability to correctly identify facial expressions of emotions. Specifically, we hypothesized that greater current psychiatric symptoms and insecure attachment would be related to difficulties in deciphering facial expressions of negative emotions.

\section{METHODS}

\section{Participants}

A total of 56 psychiatry residents were included in the study: $53.57 \%(n=30)$ of them were men and $46.42 \%(n=26)$ were women with a mean age of 26.3 years (range $24-30$ years).

These are physicians who are studying the Psychiatry specialty, which lasts for four years. This sample was distributed according to the year of training: 22 participants from the first year of training (R1), 14 from the second (R2), and 20 from the third year of training (R3). 
All residents belonged to the same training program from the National Autonomous University of Mexico (UNAM) and were receiving their training at the same institution.

The control group comprised 50 university students from degree courses other than the mental health field: Architecture 8, Communication 6, Industrial Design 4, Engineering 4, History 4, Biology 4, Music 3, Sociology 3, Political Science 3, Law 2, Philosophy 2, Visual Arts 2, Cinema 1, Physics 1, Computer Science 1, Administration 1, Hispanic Literature 1. A total of $48 \%(n=24)$ were men and $52 \%(n=26)$ were women with a mean age of 23.7 years (range 22-34 years).

\section{Tests}

In order to evaluate subjects' psychiatric symptoms, a validated Spanish version ${ }^{17}$ of the Symptom Checklist (SCL-90) ${ }^{18}$ Likert type scale was administered to all subjects. This instrument consists of 90 items which evaluate 9 dimensions (somatization, obsessions and compulsions, interpersonal sensitivity, depression, anxiety, hostility, phobic anxiety, paranoid ideation and psychoticism) and three global indexes (global severity index, positive distress and total positive symptoms). Each of the items is scored on a range from 0 to 4 where: $0=$ No, $1=$ A little, 2=Sometimes, 3=Quite, $4=$ Too much. This scale was applied in a pencil-and-paper version.

For the assessment of attachment styles, the Attachment Styles Questionnaire (ASQ) ${ }^{19}$ was applied. Fifty-one of the 60 psychiatry residents answered the Attachment Style Questionnaire (ASQ). Unfortunately, no information on attachment style could be obtained for the control group.

The ASQ is a 40-item questionnaire with alpha coefficients ranging from 0.76 to 0.84 on five scales (confidence, discomfort with closeness, relationships as secondary, need for approval, preoccupation). A validated version in Spanish was used. ${ }^{20}$ The results in the Likert scale were: $1=$ completely disagree, $2=$ disagree strongly, $3=$ moderately disagree, 4=moderately agree, $5=$ strongly agree and $6=$ completely agree.

In order to examine the ability to recognize facial expressions of emotion, we chose the Pictures of Facial Affect (POFA), ${ }^{21}$ which consist of 110 black and white photographs depicting six basic emotions (happiness, fear, anger, sadness, surprise, disgust) and a neutral expression.

This instrument has been used in a Spanish-speaking sample from the northern region of Mexico and an important cultural and linguistic finding was that the term "anger" had to be translated into "enojo" rather than "ira". The distinction is important because it may involve semantic aspects and customs that may create a bias during rapid information processing, since each photograph is presented for a period of 10 seconds.

As a result of this translation, there was a high level of agreement in the recognition of the facial expression of this emotion, as has been found in other transcultural studies. ${ }^{22}$ A modification of Ekman's (POFA) instrument was used in
Mexico City to study emotion recognition in university students, workers and psychiatric patients. Similar results to the ones reported in other countries were obtained. ${ }^{23}$

\section{Procedure}

After giving informed consent in writing, all subjects answered the ASQ and the SCL-90 before the POFA procedure was administered.

Afterwards, each participant had an appointment in a $7 \mathrm{~m}$ by $4 \mathrm{~m}$ room to answer the ASQ and SCL-90 questionnaires. After this procedure and in the same place, participants were asked to sit on a chair $3 \mathrm{~m}$ from a screen onto which the POFA was projected onto a white wall. The POFA is an instrument of continuous application and cannot be stopped once it has started. It consists of 110 black and white pictures with a 10second period of exposure. The total length of application of the POFA is of 18 minutes and 33 seconds.

\section{Statistical analysis}

All analyses were carried out using version 17.0 of the SPSS statistical software. Facial emotion recognition comparison among psychiatry residents (R1, R2 and R3) was performed by one-way ANOVA followed by Bonferroni correction. For differences between psychiatry residents and controls a Student's t was applied. Pearson correlation coefficients were used to determine linear associations between SCL-90 subscale scores and percentage of adequate facial emotion recognition, and also used to determine linear association between attachment styles and percentage of adequate facial emotion recognition. The significance level for tests was established at $\alpha \leq 0.05$.

\section{RESULTS}

\section{Emotion recognition}

Psychiatric residents. There were no significant differences in the recognition of facial expressions of emotions when the statistical analysis was performed between groups (R1 vs R2 vs R3): happiness $\mathrm{F}=2.19,2 \mathrm{gl}, p=0.12$; sadness $\mathrm{F}=1.01,2 \mathrm{gl}$, $p=0.37$; fear $\mathrm{F}=1.79,2 \mathrm{gl}, p=0.17$; anger $\mathrm{F}=0.40,2 \mathrm{gl}, p=0.66$; surprise $\mathrm{F}=0.29,2 \mathrm{gl}, p=0.74$; disgust $\mathrm{F}=0.45,2 \mathrm{gl}, p=0.63$; neutral F=0.01, 2gl, $p=0.98$.

Psychiatric residents and control group. Control group, $64.5 \%$ recognized fear significantly less when compared with psychiatry residents, $73.8 \%(t(104)=2.043 p=0.04)$. Most emotions were clearly identified by all residents, more so than in the control group: happiness $(\mathrm{t}[104]=1.91 p=0.06)$, sadness $(\mathrm{t}[104]=1.82 p=0.07)$, anger $(\mathrm{t}[104]=1.64 p=0.10)$, surprise $(\mathrm{t}[104]=1.22 p=0.22)$, disgust $(\mathrm{t}[104]=0.72 p=0.47)$ and neutral expression $(\mathrm{t}[104]=1.43 p=0.15)$. 


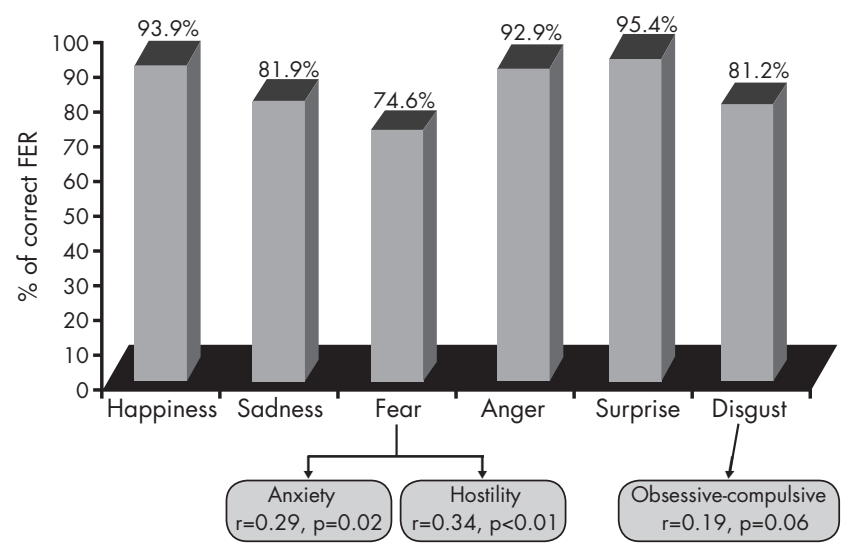

Figure 1. Facial emotion recognition and psychiatric symptoms in psychiatry residents.

\section{Psychiatric symptoms and facial emotion recognition}

Controls had higher ratings in 8 of the 9 psychiatric symptoms measured with the SCL-90 (table 1).

In the psychiatry residents' group, there was a significantly positive correlation between hostility and fear recognition $(\mathrm{r}=0.34, p=0.01)$ and anxiety and fear recognition $(\mathrm{r}=0.29, p=0.02)$. The same was observed between obsessivecompulsive symptoms and disgust recognition (figure 1). In the control group, there was a significantly negative correlation between paranoid ideation and phobic anxiety with sadness recognition (figure 2).

\section{Attachment style and facial emotion recognition}

Attachment style. The mean scores of the subscales were as follows: avoidant style (46.7 \pm 8.0$)$, anxious style (33.9 \pm 7.2$)$, confidence style $(35.7 \pm 4.9)$, uncomfortable with proximity (30.4 \pm 6.3$)$, relationships as being secondary $(16.0 \pm 4.0)$, need of recognition (19.0 \pm 5.1 ) and preoccupation (23.4 \pm 5.7$)$, suggesting that there is a tendency for residents to display an

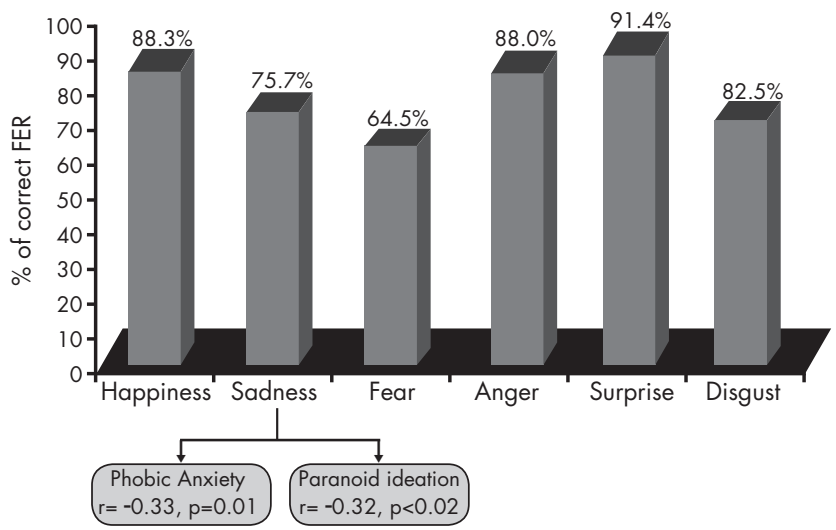

Figure 2. Facial emotion recognition and psychiatric symptoms in control subjects.

avoidant style and a low need for recognition. Several significant correlations emerged between different attachment styles and correctly identified emotions. Happiness recognition was positively related to an attachment style based on confidence $(\mathrm{r}=0.35, p=0.009)$, while sadness recognition $(\mathrm{r}=-0.28, p=0.03)$ and surprise recognition $(\mathrm{r}=0.29, p=0.03)$ correlated negatively with an attachment style based on considering relationships as something secondary. No other associations were observed between emotion recognition and attachment style (figure 3).

\section{DISCUSSION}

Emotion recognition in patients with psychiatric disorders is essential in regard to both diagnosis and treatment. Little is known about the way the skills of health professionals, including physicians, are influenced by their emotional state and attachment style.

Previous research has demonstrated that the recognition of facial expressions of emotion at the beginning of an interaction facilitates the establishment of adequate verbal communication. ${ }^{24}$ Conversely, poor communication can de-

Table 1. Comparison of the SCL-90 scores between psychiatry residents and control subjects

\begin{tabular}{|c|c|c|c|c|c|}
\hline \multirow[b]{2}{*}{ SCL-90 subscales } & \multicolumn{2}{|c|}{$\begin{array}{c}\text { Psychiatry } \\
\text { residents } \\
(n=56)\end{array}$} & \multicolumn{2}{|c|}{$\begin{array}{c}\text { Control } \\
\text { subjects } \\
(n=50)\end{array}$} & \multirow[b]{2}{*}{ Statistics } \\
\hline & Mean & S.D. & $\overline{M e a n}$ & S.D. & \\
\hline Somatization & 0.41 & 0.30 & 0.61 & 0.44 & $t=-2.8, \mathrm{df} 108, p=0.005$ \\
\hline Obsessive-compulsive & 0.74 & 0.48 & 1.12 & 0.61 & $t=-3.7$, df $108, p<0.001$ \\
\hline Interpersonal sensitivity & 0.57 & 0.42 & 0.72 & 0.47 & $t=-1.7$, df $108, p=0.09$ \\
\hline Depression & 0.53 & 0.42 & 0.74 & 0.53 & $t=-2.2$, df $108, p=0.02$ \\
\hline Anxiety & 0.52 & 0.34 & 0.71 & 0.55 & $t=-2.1$, df $108, p=0.03$ \\
\hline Hostility & 0.34 & 0.37 & 0.67 & 0.59 & $t=-3.5$, df $108, p=0.001$ \\
\hline Phobic anxiety & 0.15 & 0.27 & 0.31 & 0.38 & $t=-2.5$, df $108, p=0.01$ \\
\hline Paranoid ideation & 0.37 & 0.49 & 0.65 & 0.61 & $t=-2.6, \mathrm{df} 108, p=0.01$ \\
\hline Psychoticism & 0.08 & 0.14 & 0.23 & 0.33 & $t=-3.0$, df $108, p=0.003$ \\
\hline General severity index & 0.43 & 0.28 & 0.66 & 0.40 & $t=-3.3$, df $108, p=0.001$ \\
\hline
\end{tabular}




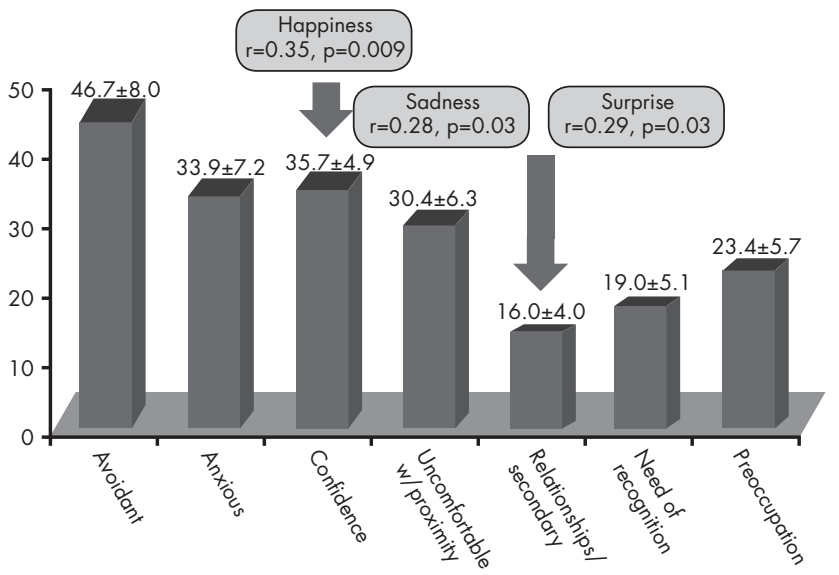

Figure 3. Attachment styles and facial emotion recognition in psychiatry residents.

stroy relationships over time, ${ }^{25,26}$ which can be particularly detrimental to the patient-therapist relationship, because interaction and establishing inter-subjectivity is one if not the most important tool in psychiatric treatment. In light of the importance of nonverbal communication for social interaction, we expected that mental health professionals -including those in training- had sufficient skills to be able to recognize emotional facial expressions, which, however, would be influenced by current psychiatric symptoms and variation in attachment style.

To rule out the possibility that psychiatric residents might over-express psychiatric symptoms, we compared the resident group with a comparable group students from other degree courses unrelated to mental health in order to look for evidence related to the importance of receiving training in the recognition of facial expressions of emotions in mental health professionals, as suggested by the Csukly et al. study. ${ }^{16}$ Students from other disciplines scored even higher in psychiatric symptoms than psychiatry residents, a finding that is inconsistent with the view that students of psychology and medicine are psychologically less stable than others. This should be studied in greater depth since there is no consistent explanation for this statement.

As regards emotion recognition, psychiatric residents were quite good at identifying the basic facial emotions. However, a number of residents had at least some difficulties in recognizing facial emotions and mistook certain facial emotions for other emotional states, a finding that is potentially detrimental in terms of patient-therapist relationship. For example, in $10.9 \%$ of residents, 4 out of 10 expressions of fear were incorrectly interpreted. Similarly, $20 \%$ of residents identified less than $60 \%$ of sad expressions correctly. Conversely, we found that current psychological problems influenced residents' ability to recognize facial emotions. In particular, fear recognition was higher in residents with high anxiety and hostility scores, and obsessive compulsive traits were linked with the recognition of disgust. These correla- tions between an internal trait with an emotion expressed in the face of another could imply that an internal experience (hostility/anxiety-fear, obsessive/compulsivity-disgust) in one individual facilitates the recognition of a related emotional state in another individual (fear) probably through intersubjective resonance. ${ }^{27}$

The finding of a correlation between avoidant attachment and poor recognition of sadness and surprise is consistent with previous reports, ${ }^{7}$ and could imply deficits in engaging in interactions as an unconsciously acquired strategy to deactivate the attachment system and protect the individual from the retrieval of painful emotional memories.

The study has several limitations. For one, the sample size was fairly small, meaning that replication in a larger sample is required. Second, we were able to recruit residents from only one medical school, so it would be useful to compare findings in residents from other schools. As such, the study can only be regarded as preliminary.

In spite of these limitations, this is one of the first studies to examine emotion recognition abilities in medical professionals, and the association of this ability with psychiatric symptoms and attachment style.

Considering the fact that there were no significant differences in facial expression of emotion recognition between groups of residents (R1 vs. R2 vs. R3), it is useful to consider carrying out a longitudinal follow up of the four years of training in order to determine whether the absence of differences is due to the small sample size or due to the cross-sectional analysis which does not consider individual variations.

Due to the limitations of this study, it would be important to have a sample of psychiatric residents from other institutional programs in order to determine whether there are differences or similarities.

We consider the longitudinal study of these factors in the academic training of psychiatrists important because of the effect on the diagnosis and the therapeutic relationship of physician and patient. In any event, training in facial emotion recognition and "body language", as we say, might be a useful part of educational curricula in medicine and clinical psychology.

\section{Authors' contribution}

The authors participated in all the procedures of the present study and read and approved the final version of the manuscript.

\section{ACKNOWLEDGEMENTS}

We are grateful for the comments and suggestions of the reviewers and the collaboration of all the students and psychiatric residents who participated in this study. And Suzanne Stephens for proofreading the English. This research was supported by project 2399 of the National Institute of Psychiatry Ramón de la Fuente Muñiz, Mexico, DF. 


\section{REFERENCES}

1. Fasel B, Luettin J. Automatic facial expression analysis: a survey. Pattern Recognition 2003;36:259-275.

2. Leber S, Heidenreich T, Stangier U, Hofmann SG. Processing of facial affect under social threat in socially anxious adults: mood matters. Depression Anxiety 2009; (1091-4269)26:196-206.

3. Vrugt A, Vet C. Effects of a smile on mood and helping behavior. Social Behavior Personality International J 2009;37:1251-1257.

4. Hinsz VB, Tomave JA. Smile and (half) the world smiles with you, frown and you frown alone. Personality Social Psychology Bull 1991;17:586-592.

5. Mineka S. A primate model of phobic fears. En: Eysenck, HJ, Martin I (eds.). Theoretical foundations of behaviour therapy. New York: Plenum Press; 1987; pp. 81-111.

6. Ekman P, Oster H. Facial expressions of emotion. Annual Review Psychology 1979;30:527-554.

7. Guterman $\mathrm{O}$. Adult attachment style and sensitivity to non-verbal expressions of emotion: The facilitating role of attachment security. Unpublished doctoral dissertation. Rama Gan, Israel: Bar-In University; 2006.

8. Mikulincer M, Shaver P. Attachment in adulthood, structure, dynamics and change. New York: The Guilford Press; 2007; pp, 25.

9. Dykas M, Cassidy J. Attachment and the processing of social information across the life span: Theory and evidence. Psychological Bull 2011;137(1):19-46.

10. Machado P, Beutler L, Greenberg L. Emotion recognition in psychotherapy: Impact of therapist level of experience and emotional awareness. J Clinical Psychology 1999;55(1):39-57.

11. Forrest D. Teaching affect recognition to medical students: Evaluation and reflections. J American Academy Psychoanalysis Dynamic Psychiatry 2011;39(2):229-241.

12. Grant EC. An ethological description of non-verbal behaviour during interviews. British J Medical Psychology 1968;41:177-183.

13. Schelde T, Hertz M. Ethology and psychotherapy. Ethology Sociobiology 1994;15:383-392.

14. Geerts E, Bouhuys AL, van den Hoofdakker RH. Nonverbal attunement between depressed patients and an interviewer predicts subsequent improvement. J Affective Disorders 1996;40:15-21.
15. Troisi A. Ethological research in clinical psychiatry: the study of nonverbal behavior during interviews. Neuroscience Biobehavioral Reviews 1999;23:905-913.

16. Csukly G, Czobor P, Simon L, Takács B. Basic emotions and psychological distress: association between recognition of facial expressions and Symptom Checklist-90 subscales. Comprehensive Psychiatry 2008;49:177-183.

17. Cruz Fuentes C, López Bello L, Blas García C, González Macías L et al. Datos sobre la validez y confiabilidad de la SYMPTOM CHECK LIST 90 (SCL 90), en una muestra de sujetos mexicanos. Salud Mental 2005;20(1):72-81.

18. Degoratis L. SCL-90-R Symptom Checklist-90-R [Computer software]. NCS, 1994.

19. Feeney JA, Noller P, Hanrahan M. Assessing adult attachment. In: Sperling MB, Berman WH (eds.). Attachment in adults: Clinical and developmental perspectives, New York: Guilford Press; 1994; pp. 128-152.

20. Ahumada Castillo JP. Traducción y validación del cuestionario de estilos de apego en el adulto (Attachment Style Questionnaire). México: Tesis de especialidad en Psiquiatría, UNAM; 2011.

21. Ekman P. Pictures of facial affect (POFA). $18 \mathrm{~min}$. 1-110. PAUL EKMAN GROUP, LLC; 1993.

22. Anguas-Wong AM, Matsumoto D. Reconocimiento de la expresión facial de la emoción en mexicanos universitarios. Revista Psicología 2007;XXV(2):279-293.

23. Pérez-Rincón H, Cortés J, Díaz-Martinez A. El reconocimiento de la expresión facial de las emociones. 1999;22(1):17-23.

24. Mueser KT, Doonan R, Penn DL, Blanchard JJ et al. Emotion recognition and social competence in chronic schizophrenia. J Abnormal Psychol 1996;105(2):271-275.

25. Hooker C, Park S. Emotion processing and its relationship to social functioning in schizophrenia patients. Psychiatry Research 2002;112(1):41-50.

26. Poole JH, Tobias FC, Vinogradov S. The functional relevance of affect recognition errors in schizophrenia. J International Neuropsychology Soc 2000;6:649-58.

27. Gallese V. The roots of empathy: the shared mainfold hypothesis and the neural basis of intersubjectivity. Psychopathology 2003; 36:171-180.

Declaration of conflict interest: None 